\title{
EVALUASI PELAKSANAAN SISTEM LOKASI PENYIMPANAN DESENTRALISASI REKAM MEDIS DI RS SYUHADA HAJI BLITAR
}

\author{
Kartika Sari Wanodya ${ }^{1}$, Wahyudi Istiono ${ }^{2}$ \\ ${ }^{1}$ Diploma III Rekam Medis Sekolah Vokasi Universitas Gadjah Mada \\ ${ }^{2}$ Fakultas Kedokteran UGM Universitas Gadjah Mada \\ Email: ${ }^{1}$ kartikaswanodya@gmail.com, ${ }^{2}$ wistiono@gmail.com
}

\begin{abstract}
This research aimed to evaluate the implementation of the decentralized storing system in the Syuhada Haji Blitar Hospital. The type of research is descriptive research using a qualitative approach with phenomenological research design. Research subjects were 11 medical record officers, two nurses, and a nurse assistant. The research object is the file storage system. Main factors of decentralized storing are policy and fund allocation. SNF and chronological storage alignment are used. The existence of file unification for continuity. Nurses and nursing assistants do acceptance and storage. The report is done manually and computerized and a plan to convert to centralized storage Obstacles: Filing is done by everyone, there are accumulations of unprocessed files, paper map usage, numbers are not jutting out, and there are no trolleys. Impact: misfiling due to lack of usage of tracer, duplication due to wrong searching in the system and misfiling, length of hours of inpatient file search, a patient file is more than one, checking from start again
\end{abstract}

Keyword: Evaluation, Decentralization, medical record

\begin{abstract}
ABSTRAK
RS Syuhada Haji Blitar menggunakan sistem lokasi penyimpanan rekam medis secara desentralisasi. Terdapat empat tempat penyimpanan rekam medis yaitu di TPP IGD dan rawat inap, TPP poliklinik umum, TPP klinik kandungan, serta di unit rekam medis. Sistem penjajaran yang digunakan ialah SNF dan secara kronologis. Dampak yang sementara terlihat ialah missfile, duplikasi dan komplain. Mengevaluasi pelaksanaan sistem penyimpanan desentralisasi dengan jenis penelitian deskriptif kualitatif, rancangan penelitian fenomologis. Subjek penelitian yaitu 11 petugas rekam medis, 2 perawat, 1 asisten perawat. Objek penelitian yaitu sistem penyimpanan berkas. Faktor yang mendasari adalah kebijakan dan alokasi dana. Penjajaran menggunakan SNF dan penyimpanan kronologis. Adanya penyatuan berkas untuk kesinambungan. Perawat dan asisten perawat melakukan penerimaan dan penyimpanan. Pelaporan secara manual dan komputerisasi. terdapat rencana pengubahan ke penyimpanan sentralisasi.Hambatan: filing dikerjakan semua orang, penumpukan berkas yang belum diolah, tidak ada trolly. Dampak : missfile karena tracer tidak digunakan, duplikasi akibat salah pencarian di sistem dan akibat missfile, lama pencarian berkas rawat inap, berkas pasien lebih dari satu, terjadi pemeriksaan dari awal kembali.
\end{abstract}

Kata Kunci: Evaluasi, Desentralisasi, Rekam medis 


\section{PENDAHULUAN}

Penyelenggaraan rekam medis adalah kegiatan pelayanan penunjang secara profesional yang berorientasi pada kebutuhan informasi kesehatan bagi pemberi layanan kesehatan, administrator, dan manajemen pada sarana layanan kesehatan dan instansi lain yang berkepentingan berdasarkan pada ilmu pengetauhan dan teknologi rekam medis ${ }^{[8]}$.

Penyimpanan berkas rekam medis yang baik merupakan hal yang sangat penting guna kelancaran pelayanan kesehatan yang akan diberikan kepada pasien. Penyimpanan berkas rekam medis juga harus memudahkan petugas dalam pencarian berkas saat dibutuhkan. Ada enam unsur yang berkaitan dengan penyimpanan yaitu mudah diakses, berkualitas, menjaga keamanan (security), fleksibilitas, dapat dihubungkan dengan berbagai sumber (connectivity) dan efisien [4].

Sistem penyimpanan rekam medis secara desentralisasi sudah tidak dianjurkan untuk digunakan karena keseluruhan data pasien tidak dapat disediakan secara cepat pada waktu yang bersamaan dikarenakan petugas harus mengambil rekam medis di tempat yang berbeda-beda ${ }^{[12]}$. Selain itu juga menimbulkan terjadinya salah simpan, duplikasi dan ketidaksinambungan informasi data pasien. Agar tersedia satu gambaran lengkap mengenai riwayat penyakit dan pengobatan seorang pasien. Di rumah sakit Syuhada Haji Blitar, terdapat empat tempat penyimpanan rekam medis yaitu di TPP IGD dan rawat inap, TPP poliklinik umum, TPP klinik kandungan, serta di unit rekam medis.
Setiap pasien lama rawat inap dan IGD yang datang akan diberikan berkas rekam medis baru dengan nomor pertama kali pasien berkunjung, sedangkan untuk pasien rawat jalan klinik pasien lama tetap menggunakan berkas rekam medis lama untuk pemeriksaan (unit numbering system). Filing dikerjakan oleh semua petugas unit rekam medis. Sistem penjajaran yang digunakan straight numerical filing sedangkan cara penyimpanan di klinik kandungan berdasarkan kronologis. Dampak yang sementara terlihat dianaranya terjadi duplikasi rekam medis, terdapat rekam medis yang tidak ditemukan (missfile), adanya komplain dari tenaga kesehatan lain sehingga menghambat pelayanan yang akan diberikan.

Dari latar belakang tersebut muncul pertanyaan peneliti yang menjadi rumusan masalah yaitu Bagaimana pelaksanaan sistem penyimpanan desentralisasi di unit rekam medis RS Syuhada Haji Blitar.

Tujuan dari penelitian ini untuk mengevaluasi pelaksanaan sistem penyimpanan desentralisasi, sedangkan manfaat penelitian ini yaitu sedangkan manfaat penelitian ini yaitu pertama bagi institusi pendidikan untuk menambah wawasan ilmiah, kedua bagi tempat penelitian sebagai alat evaluasi mengenai pengelolaan rekam medis di pelayanan kesehatan, ketiga bagi mahasiswa atau peneliti lain dapat menjadi refrensi pembelajaran.

\section{METODE PENELITIAN}

Desain penelitian yang digunakan yaitu penelitian deskriptif dengan pendekatan kualitatif dan jenis rancangan 
fenomologis. Subjek penelitian pada penelitian ini yaitu empat belas informan yang terdiri dari 11 petugas rekam medis, 2 perawat dan 1 asisten perawat. Objek yang diteliti yaitu sistem penyimpanan berkas rekam medis. Teknik pengumpulan data dengan studi dokumentasi, wawancara, dan observasi. Hasil penelitian diuji keabsahan datanya dengan triangulasi sumber data.

\section{HASIL DAN PEMBAHASAN}

Faktor yang mendasari pelaksanaan sistem penyimpanan desentralisasi

Faktor yang mendasari pelaksanaan sistem penyimpanan secara desentralisasi ialah kebijakan dan alokasi dana yang belum memungkinkan untuk menjadikan sentralisasi. Kebijakan merupakan dasar rencana dalam melakukan suatu pekerjaan [2].

Deskripsi sistem penyimpanan rekam medis di RS Syuhada Haji Blitar

a. Alur berkas rekam medis

Alur berkas rekam medis di RS Syuhada Haji Blitar dimulai dari TPP poliklinik umum, rawat inap dan IGD, klinik kandungan. Setelah itu berkas berada pada ruang pemeriksaan/bangsal dan kemudian dilakukan pengolahan data sebelum kembali ke filing. Filing berada di tiap TPP dan unit rekam medis untuk pasien rawat inap. Penempatan ruang penerimaan pasien sebaiknya berada di dekat dengan ruangan pelayanan rawat jalan, rawat inap, atau rawat darurat, selain itu tempat penerimaan pasien juga terletak di dekat ruang penyimpanan berkas rekam medis ${ }^{[1]}$. Penyimpanan di unit rekam medis RS Syuhada Haji Blitar belum berada didekat tempat penerimaan. b. Sistem penjajaran yang digunakan dalam peyimpanan

Sistem penjajaran yang digunakan ialah SNF, atau sistem penomoran langsung [1]. Namun pada penyimpanan di TPP klinik kandungan disimpan berdasarkan kronologis. Pada SOP dan kebijakan tertulis bahwa sistem penjajaran yang digunakan ialah SNF sehingga penyimpanan di klinik kandungan belum sesuai dengan SOP dan kebijakan.

c. Adanya penyatuan berkas rekam medis lama dan baru untuk menjaga riwayat kesinambungan pasien

Rekam medis yang lengkap dan berkesinambungan sangat diperlukan untuk keperluan evaluasi pelayanan yang telah diberikan kepada pasien [6]. Guna mencapai kesinambungan, berkas pasien lama dan baru akan disatukan di penyimpanan unit rekam medis, dan berkas yang berada di penyimpanan TPP akan dibawa ke unit rekam medis jika rak penyimpanan sudah penuh.

d. Pembagian kerja dalam pelaksanaan sistem penyimpanan rekam medis

Pembagian kerja adalah informasi tertulis yang menguraikan tugas dan tanggung jawab, kondisi pekerjaan, dan aspek-aspek pekerjaan pada suatu jabatan tertentu dalam organisasi [3]. Pembagian kerja di RS Syuhada Haji Blitar sudah tertulis dalam pedoman pengorganisasian unit rekam medis, namun pada penerimaan dan penyimpanan berkas di rawat jalan dilakukan oleh perawat dan asisten perawat, dimana seharusnya dilakukan oleh sumber daya manusia dengan minimal pendidikan SMU/sederajat dan sudah mendapatkan pelatihan rekam medis, sehingga belum 
terdapat informasi tertulis mengenai perawat dan asisten perawat membantu tugas rekam medis.

\section{e. Pelaporan}

Setiap rumah sakit wajib melaksanakan sistem informasi rumah sakit (SIRS). SIRS adalah suatu proses pengumpulan, pengolahan, dan penyajian data rumah sakit. Pengolahan data dilakukan secara manual dan komputerisasi [11]. Wewenang yang dimiliki oleh tenaga rekam medis dengan tingkat pendidikan D3 diantaranya adalah melaksanakan evaluasi kelengkapan diagnosa, serta melaksanakan pengumpulan, validasi, dan verifikasi data sesuai ilmu statistik rumah sakit ${ }^{[10]}$. RS Syuhada Haji Blitar telah melakukan pelaporan secara manual dan komputerisasi, namun evaluasi kelengkapan diagnosis pada rawat jalan dilakukan oleh perawat dan asisten perawat yang bukan berlatar belakang pendidikan D3 rekam medis.

$f$. Rencana mengunakan sistem penyimpanan rekam medis secara sentralisasi

Pengarsipan adalah susunan catatan yang sistematis dalam urutan tertentu sehingga referensi dan pengambilannya cepat dan mudah [5]. Pihak unit rekam medis RS Syuhada Haji Blitar kedepannya akan merubah sistem penyimpanan secara desentralisasi ke sentralisasi. Hal ini terkait pentingnya kesinambungan pasien,serta mengingat banyaknya kekurangan dari sistem penyimpanan desentralisasi yang mengakibatkan kurang optimalnya dalam membantu meningkatkan mutu pelayanan yang diberikan kepada pasien.
Hambatan dalam sistem penyimpanan rekam medis secara desentralisasi

a. Tugas filing dilakukan oleh semua petugas

Sumber daya manusia adalah petugas yang bertanggung jawab dan mampu berkarya secara optimal untuk mencapai tujuan organisas ${ }^{[4]}$. Filing dilakukan oleh semua petugas di TPP dan unit rekam medis.

b. Penumpukan berkas rekam medis yang belum diolah

Terjadi penumpukan berkas rekam medis rawat inap yang belum diolah karena petugas yang melakukan pengolahan data mendapat jobdesk tambahan pada bagian BPJS karena RS Syuhada Haji baru berfokus dan bekerja sama dengan asuransi terkait sehingga perlu adanya analisis pekerjaan kembali.

c. Tidak adanya alat pengangkut berkas (trolly)

Keberhasilan dari kegiatan manajemen kearsipan adalah juga secara langsung dipengaruhi oleh peralatan yang dipergunakan untuk menyimpan arsip dan efisiensi dalam pemakaian peralatan ${ }^{[12]}$. Unit rekam medis RS Syuhada Haji Biltar belum memiliki trolly sehingga penyelesaian pekerjaan menjadi kurang efektif, hal ini bisa dilihat dari petugas yang harus bolak balik dalam melakukan pengembalian berkas dan mengalihfungsikan kursi roda.

Dampak dalam sistem penyimpanan rekam medis secara desentralisasi

a. Missfile

$\begin{array}{ccr}\text { Beberapa } & \text { fasilitas } & \text { diruang } \\ \text { penyimpanan } & \text { berkas rekam medis }\end{array}$ 
diantaranya adanya tracer yang digunakan sebagai pengganti berkas rekam medis di rak filing yang dapat digunakan untuk menelusur keberadaan rekam medis ${ }^{[1]}$. Berdasarkan hasil penelitian, terdapat missfile dalam pencarian berkas rekam medis pada tempat penyimpanan pasien rawat inap, rawat jalan poliklinik dan klinik kandungan, hal ini disebabkan karna tidak digunakannya tracer dalam pengambilan berkas meskipun sudah terdapat kebijakan yang mengatur tentang penggunaan tracer.

\section{b. Duplikasi}

Terdapat duplikasi nomor rekam medis pada satu tempat penyimpanan, hal ini terjadi karena petugas salah menulis nama atau pihak pasien salah memberikan informasi jika lupa membawa KIB atau kartu identitas dan akibat dari missfile. Berkas rekam medis yang memiliki duplikasi nantinya akan disatukan dengan berkas yang lama dan nomor yang digunakan ialah nomor terbaru atau nomor rekam medis pasien terakhir berkunjung.

c. Lama dalam pencarian berkas rekam medis

Waktu penyediaan berkas yaitu rawat jalan $\leq 10$ menit, sedangkan rawat inap $\leq 15$ menit[7]. Penyediaan berkas rekam medis di RS Syuhada Haji Blitar untuk pasien rawat darurat dan poliklinik rata rata 3 menit jika berkas masih berada di rak penyimpanan TPP, sedangkan pencarian berkas rawat inap memerlukan waktu lebih dari 15 menit. Lamanya pencarian berkas rekam medis dirawat inap menimbulkan komplain dari tenaga kesehatan lain, komplain tersebut dapat berupa telpon guna mengingatkan kembali petugas rekam medis. d. Satu pasien dapat memiliki banyak berkas rekam medis ditempat yang berbeda

Rekam medis yang lengkap dan berkesinambungan sangat diperlukan untuk keperluan evaluasi pelayanan yang telah diberikan kepada pasien ${ }^{[6]}$. Penyimpanan secara desentralisasi di RS Syuhada Haji blitar menyebabkan satu pasien yang pernah melakukan rawat jalan, rawat darurat dan rawat inap akan memiliki lebih dari satu berkas rekam medis di tempat penyimpanan yang berbeda sehingga susah mewujudkan kesinambungan .

e. Dilakukan pemeriksaan dari awal kembali oleh tenaga kesehatan

Manfaat rekam medis adalah untuk pengobatan pasien, rekam medis bermanfaat sebagai dasar dan petunjuk untuk merencanakan pengobatan, perawat, dan tindakan medis yang harus diberikan kepada pasien[9]. Penyimpanan secara desentralisasi serta setiap pasien rawat darurat dan rawat inap yang selalu dibuatkan berkas rekam medis baru, mengakibatkan terjadinya pemeriksaan dari awal kembali, hal ini disebabkan karena tidak tahunya tentang riwayat obat yang diberikan, DPJP terdahulu. Tenaga kesehatan lebih sering meminta berkas rekam medis pasien yang masih di filing TPP IGD karena jika sudah dipindahkan ke unit rekam medis penyediaan berkas akan membutuhkan waktu yang lama sehingga lebih memilih melakukan pemeriksaan dari awal.

\section{SIMPULAN}

Terdapat dua faktor yang mendasari pelaksanaan penyimpanan yaitu kebijakan 
tentang penyimpanan dan alokasi dana belum memungkinkan menjadikan sentralisasi, sistem penjajaran pada kebijakan dan SOP adalah SNF tapi tidak diterapkan pada penyimpanan klinik kandungan. Perawat dan asisten perawat melakukan penyimpanan, penerimaan tanpa ada kebijakan maupun SOP bahwa terdapat tugas tambahan dari unit rekam medis. Pelaporan secara manual dan komputerisasi. Adanya rencana ke sentralisasi agar penyimpanan menjadi sistematis.Terdapat kebijakan penggunaan tracer namun tidak dilaksanakan, waktu pencarian berkas rawat inap lebih dari 15 menit dan menimbulkan komplain dari tenaga kesehatan. Berkas lebih dari satu dan terjadi pemeriksaan dari awal sehingga sulit mewujudkan berkesinambungan.

Beberapa langkah yang dapat dilakukan untuk menanggulangi temuan tersebut meliputi: (a) Unit rekam medis sebaiknya perlu melakukan perencanaan jika kedepannya akan mengubah sistem penyimpanan menjadi sentralisasi; (b) Unit rekam medis sebaiknya melakukan analisis pekerjaan agar tidak ada penumpukan pekerjaan ,komplain dari tenaga kesehatan serta kegiatan filing tidak dikerjakan oleh semua orang; (c) Unit rekam medis sebaiknya memperbarui kebijakan dan SOP terkait sistem penjajaran serta penerimaan dan penyimpanan berkas yang dilakukan oleh perawat dan asisten perawat; (d) Unit rekam medis sebaiknya memanfaatkan tracer sebagai petunjuk berkas rekam medis keluar dari rak penyimpan sesuai dengan kebijakan.

\section{DAFTAR PUSTAKA}

[1] Budi, S.C. (2011). Manajemen Unit Kerja Rekam Medis. Yogyakarta : Quantum Sinergis Media

[2] Dachi, R.A. (2017) . Proses dan Analisis Kebijakan Kesehatan (Suatu Pendekatan Konseptual). www.books.google.co.id. Diakses tanggal 15 Maret 2018

[3] Hasibuan. (2007). Manajemen Sumber Daya Manusia. Jakarta: PT Bumi Aksara.

[4] Hatta, G. R. (2008). Pedoman Manajemen Informasi Kesehatan di Sarana Pelayanan Kesehatan. Jakarta : Universitas Indonesia.

[5] IFHIMA (International Federation of Health Information Management Associations). (2012). Education Module for Health Record Practice. www.ifhima.org. Diakses tanggal 14 Maret 2018.

[6] IFHRO (International Federation of Health Record Organization). (2006). Education Module For Health Record Practice. www.ifhro.org. Diakses tanggal 15 Maret 2018

[7] Kepmenkes No 129/Menkes/SK/II/2008 tentang Standar Pelayanan Minimal Rumah Sakit. www.bprs.kemkes.go.id. Diakses tanggal 15 Maret 2018.

[8] Keputusan Menteri Pendayagunaan Aparatur Negara (Menpan) No135 / Kep / Menpan/ 12/ 2002 tentang Jabatan Fungsional Perekam Medis dan Angka Kreditnya. www.menpan.go.id. Diakses tanggal 27 Januari 2018

[9] Konsil Kedokteran Indonesia. (2006). Manual Rekam Medis. www.perpustakaan.depkes.go.id. Diakses tanggal 3 Februari 2018

[10] Permenkes RI No 55 Tahun 2013 tentang Penyelenggaraan Pekerjaan Perekam Medis. www.kemhan.go.id. Diakses tanggal 14 Maret 2018 
[11] Permenkes RI No 1171 / Menkes/ Per/VI/2011 tentang Sistem Informasi Rumah Sakit. www.yankes.kemkes.go.id. Diakses tanggal 14 Maret 2018.

[12] Sugiarto , A. Wahyono, T. (2005). Manajemen Kearsipan Modern. Yogyakarta: Gava Media

[13] WHO. (2002). Medical Record Manual: A Guide For Developing Countries. World Health Organization Regional Office for The Western Pacific. www.wpro.who.int. Diakses tanggal 3 Februari 2018. 